\title{
Consumers' willingness to pay for functional rice: a survey from Indonesia
}

\author{
${ }^{1}$ Annur, N.D., ${ }^{1}$ Nugrohoningtyas, B.S.H., ${ }^{2}$ Rodríguez Dodero, M.C. and ${ }^{1, *}$ Setyaningsih, W. \\ ${ }^{I}$ Department of Food and Agricultural Product Technology, Faculty of Agricultural Technology, Gadjah \\ Mada University, Jalan Flora, Bulaksumur, 55281, Yogyakarta, Indonesia \\ ${ }^{2}$ Department of Analytical Chemistry, Faculty of Sciences, University of Cadiz, Campus de Excelencia \\ Internacional Agroalimentario (CeiA3), Campus del Rio San Pedro, 11510 Puerto Real, Cádiz, Spain
}

\section{Article history: \\ Received: 2 March 2020 \\ Received in revised form: 3 April 2020 \\ Accepted: 8 April 2020 \\ Available Online: 26 April 2020}

\section{Keywords:}

Functional rice,

Willingness to pay,

Melatonin,

Consumer studies,

Indonesia

DOI:

https://doi.org/10.26656/fr.2017.4(4).095

\begin{abstract}
Rice, especially the pigmented varieties, contains a higher level of melatonin (N-acetyl-5methoxytryptamine), which is used in treatment for sleeping disorders and for improving mood. It has potent antioxidant properties, anti-obesity, and anti-inflammatory, thus potential as the basis for functional food development. The purpose of the study was to examine how the various rice attributes and demographic characteristics affect the willingness to pay of Indonesian consumers on functional rice. Multi-Factor Categorical Design (MFCD) and Balanced Incomplete Block Design (BIBD) have been used to study multiple non-quantitative factors, including different rice varieties and health benefits information on the label $\left(x_{1}, 3\right.$ levels: white rice, brown rice-label, and red rice-label), price $\left(x_{2}, 2\right.$ levels: low and high), and rice producers ( $x_{3}, 3$ levels: international brand, established national brand, and new national brand). Data collection was administered through an online questionnaire survey to 204 respondents, living in four major Indonesian islands: Java, Bali, Sumatra, and the Moluccas. The results showed that despite the health benefits of the melatonin contained in the whole brown and red rice, Indonesian consumers still preferred conventional white rice over the aforementioned rice varieties. Price was recognized as the main attribute affecting the selection of functional rice, whilst rice producers gave less impact on willingness to pay. The results indicated that cultural value, consumers' knowledge of melatonin, consumers' health status, and consumers' income were the sources of heterogeneity in consumers' willingness to pay for functional rice.
\end{abstract}

\section{Introduction}

There has been a noticeable expansion in the global food market over the past decade. Food, which previously eaten to satisfy hunger and to provide nutrients for the body, nowadays has been marketed with additional health benefits. This novel food, labeled as a functional food, prevents nutrition-related diseases and improves the physical and mental well-being of the consumers (Siró et al., 2008). The growing interest among consumers who believe that food improves health and quality of life have raised potential markets for functional food.

To date, there are several definitions for functional foods that ranged from the very simple to the more complex. Extracting the summary of twenty-six different definitions of functional food, four general concepts are identified: the nature of food, health benefits, functions, and regular consumption. Furthermore, a working definition of functional food was formulated: "A functional food is, or appears similar to, a conventional food. It is part of the standard diet and is consumed on a regular basis, in normal quantities. It has proven health benefits that reduce the risk of specific chronic diseases or beneficially affect target functions beyond its basic nutritional functions (Doyon and Labrecque, 2008).

Rice (Oryza sativa) is the third most grown cereal crop in the world. In Indonesia, rice is the utmost staple food with a yearly consumption of more than 46,000 KT (FAO, 2017). Hence, rice is extremely important, not only to satisfy hunger but also to provide nutrients for the population of Indonesia. Several health-benefited substances have been identified in rice and these include melatonin (Setyaningsih et al., 2014). Melatonin (N- 
acetyl-5-methoxytryptamine) is an indoleamine that is synthesized from the essential amino acid L-tryptophan. It has various essential activities in the body that gives positive health advantages. Melatonin is involved in the regulation of circadian rhythms and sleep-wake patterns; therefore, it is helpful in limiting sleep disorders due to jet lag and shift work (Spiegelhalder et al., 2017). It is used for the treatment of insomnia and it increases total and quality of sleep time (Ferracioli-Oda et al., 2013). Concomitantly, melatonin has been shown to improve mood in the context of resynchronization of the altered circadian rhythms (Lanfumey et al., 2013). Additionally, the compound has also been linked to a wide range of functions, including antioxidants (Bonnefont-Rousselot and Collin, 2010), anti-obesity (Szewczyk-Golec et al., 2017), and anti-inflammation (Mauriz et al., 2013).

The level of melatonin decreases gradually in each step of rice production, particularly after milling processes to remove the bran layer of rice grain. The whole grain (brown) rice, as well as pigmented (red and black) varieties contain higher levels of melatonin than the polished (white) grain. The level of melatonin in these unpolished rice grains is maintained in the final product because there is no bran removal process (Setyaningsih et al., 2014; Setyaningsih et al., 2016). Henceforth, consumption of whole grain (brown, red, and black) rice has additional functional benefit.

Two major characteristics, sensory and non-sensory, have been identified as factors that contribute to consumers' food choices. Sensory characteristics, especially the taste, have been claimed to be the most critical variables directing consumers' food choice (Verbeke, 2006; Urala and Lähteenmäki, 2007). While non-sensory characteristics such as brand, claim, price (Ares et al., 2010), and convenience (Urala and Lähteenmäki, 2003) also likely to affect the consumers' food choice.

The notion that there may be individual differences in the extent to which they are likely to buy products with functional properties (Frewer et al., 2003), determines factors that influence consumers' willingness to buy functional food in Indonesia is important. This research examined the influence of different levels of information through the acceptance and willingness to pay using a survey. Therefore, the aims of this study were to study how the various rice attributes and demographic characteristics affect the willingness to pay of Indonesian consumers on functional rice.

\section{Materials and methods}

\subsection{Participants}

A total of 204 participants lived in Indonesia's main islands, namely Sumatra, Java, Bali, and the Moluccas, partook the online survey. Non-probability sampling with convenience choice and snowball sampling was used in this study. The age of participants was chosen between 20 and 55 years old because a person with that range of age was responsible for food grocery shopping in the household. The participants used their electronic devices to complete the online questionnaire.

\subsection{Questionnaire and research design}

The consumer data were collected through an online consumer questionnaire survey. Before being administered, the initial version of the questionnaire was validated on a pilot sample of 10 respondents which two of them were experts. The final version of the questionnaire consisted of a structured and unstructured questionnaire. The questionnaire was divided into four parts.

The participants filled in a questionnaire on their willingness to pay for functional rice over multiple nonquantitative factors. Three attributes were used in this study: label ( $x_{1}, 3$ levels), price $\left(x_{2}, 2\right.$ levels), and rice producers $\left(x_{3}, 3\right.$ levels). The attributes and levels used in the study are summarized in Table 1 . Considering the number of product attributes and levels, a multi-factor categorical design generated 18 functional rice profiles. These profiles were presented to consumers using pictures on the online questionnaire (Figure 1).

Table 1. Rice product attributes and level considered for willingness to pay analysis

\begin{tabular}{ccl}
\hline Attribute & Levels & \multicolumn{1}{c}{ Description of levels } \\
\hline Type of & 3 & 1. Regular: White rice \\
Rice & & 2. Functional: Brown rice labelled with a \\
& & 3. Functional: Red rice labelled with a \\
Price & 2 & $\begin{array}{l}\text { 1. Low } \\
\text { 2. High }\end{array}$ \\
Rice & 3 & $\begin{array}{l}\text { 1. International brand } \\
\text { Producers }\end{array}$ \\
& 2. Established national (Indonesian) brand \\
& 3. New national brand \\
\hline
\end{tabular}
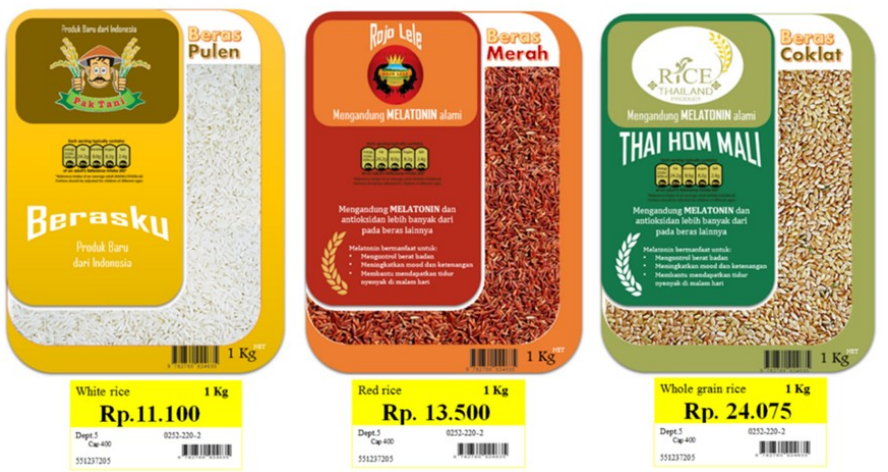

Figure 1. Some examples of rice labels used in the survey 
The picture depicted a rice label which contains the brand name, producer, rice variety, and claim for melatonin's health benefit, product weight, and price. Consumers could also see the appearance of rice product through transparent packaging. A rating was applied, requesting respondents to rate each picture with a metric willingness to pay in the scale of 1 to $7(1=\mathrm{No}$, I will not buy at all, $7=$ Yes, I will always buy).

Prices were set according to what observed in the market for polished (white), whole grain (brown), and pigmented (red) rice products. The two alternatives differed in terms of the price of white, brown and red rice grains were as follows: $11,100 \mathrm{IDR} / \mathrm{kg}$ and 19,950 IDR/kg; 24,075 IDR/kg and $36,990 \mathrm{IDR} / \mathrm{kg} ; 13,500$ IDR/kg and 44,990 IDR/kg respectively.

To get a clear understanding regarding the willingness to pay of rice consumers when alternatives were provided, six rice products out of 18 profiles were presented to each participant using a Balanced Incomplete Block (BIB) design (ISO 2011). The participants were then required to evaluate the six rice products on the basis of the willingness to pay in a way as a consumer evaluating some products on the market shelf. The BIB design was employed because it was not advisable to rank all the 18 functional rice profiles in one assessment. Therefore, a subset of samples is selected so that, in the BIB design, every sample and all possible pairs of two samples were evaluated in an equal number of times. From the initial 18 functional rice profiles $(\mathrm{t}=18)$, a subset of six profiles $(\mathrm{k}=6)$ was chosen. The BIB design generated 51 blocks $(b=51)$ of six profiles. Every sample was replicated 17 times $(\mathrm{r}=17)$ and each pair of samples was evaluated 5 times $(\mathrm{I}=5)$. This design was repeated four times. A ranking test is more appropriate over the scoring to assess this aspect. Respondents were asked to rank all of the six-point scale profiles $(1=\mathrm{I}$ am willing to purchase, $6=\mathrm{I}$ am less willing to purchase).

The third part of the questionnaire included a list of queries to analyze respondents' attitudes towards food consumption. The perception of healthy eating habits and lifestyle was tested by providing questions related to their agreement level on this issue (using a 7- and 5-box scale). The consumption frequency of polished white rice, whole-grain or brown rice, pigmented red and black rice was asked by asking respondents to indicate if specific statements reflected their habits. In addition, the respondents were asked to choose the statement that reflects their sleeping disorder in which refers to melatonin deprivation.

The last part of the questionnaire investigated the sociodemographic characteristics of the respondents.
Age, gender, marital status, origin and place of living, occupation, educational level, housing asset, and household purchase frequency were asked. Table 2 compares respondents from the survey and the Indonesian populations based on demographic variables. Compared with national data, the data collected in this online survey was a reasonably representative sample.

Table 2. Demographic characteristics of the survey participants and the Indonesian populations

\begin{tabular}{lcc}
\hline Variable & $\begin{array}{c}\text { Respondents from } \\
\text { the survey }\end{array}$ & Indonesia \\
\hline Island & $53.92 \%$ & $52.13 \%$ \\
Java & $6.37 \%$ & $1.63 \%$ \\
Bali & $21.56 \%$ & $8.82 \%$ \\
Sumatra & $18.13 \%$ & $1.11 \%$ \\
The Moluccas & &
\end{tabular}

Age

Between 20 and 30 years old

$80.88 \%$

$43.55 \%$

Between 31 and 40 years old

$14.21 \%$

$34.04 \%$

Between 41 and 55 years old $4.90 \%$ $23.40 \%$

Gender

Male

$38.72 \%$

$50.50 \%$

Female

$61.27 \%$

$49.50 \%$

Marital status

Single

Married

$76.47 \%$

$99.98 \%$

Occupation

Private employee

Undergraduate student

Entrepreneur

$23.53 \%$

$0.02 \%$

Civil worker

$24.02 \%$

$44.61 \%$

$2.45 \%$

Housewife

$8.33 \%$

$10.34 \%$

Unemployed

$8,82 \%$

$1.72 \%$

$2.45 \%$

$1.96 \%$

$10.00 \%$

Education

Primary and secondary school

$0.98 \%$

$40.36 \%$

High school

$15.68 \%$

$37.49 \%$

University degree

$83.33 \%$

$58.47 \%$

Income

Low and middle level

$89.21 \%$

$80.00 \%$

High level

$10.78 \%$

$20.00 \%$

\subsection{Data analysis}

To understand better which rice attributes affect consumers' willingness to pay, a one-way ANOVA analysis had been applied with Friedman-type statistic and Fischer's LSD was applied. The statistical analyses were performed using STATGRAPHICS Centurion XVI (Statpoint Technologies, Inc., USA).

\section{Results and discussion}

\subsection{Willingness to pay analysis}

The willingness to pay survey explores how 

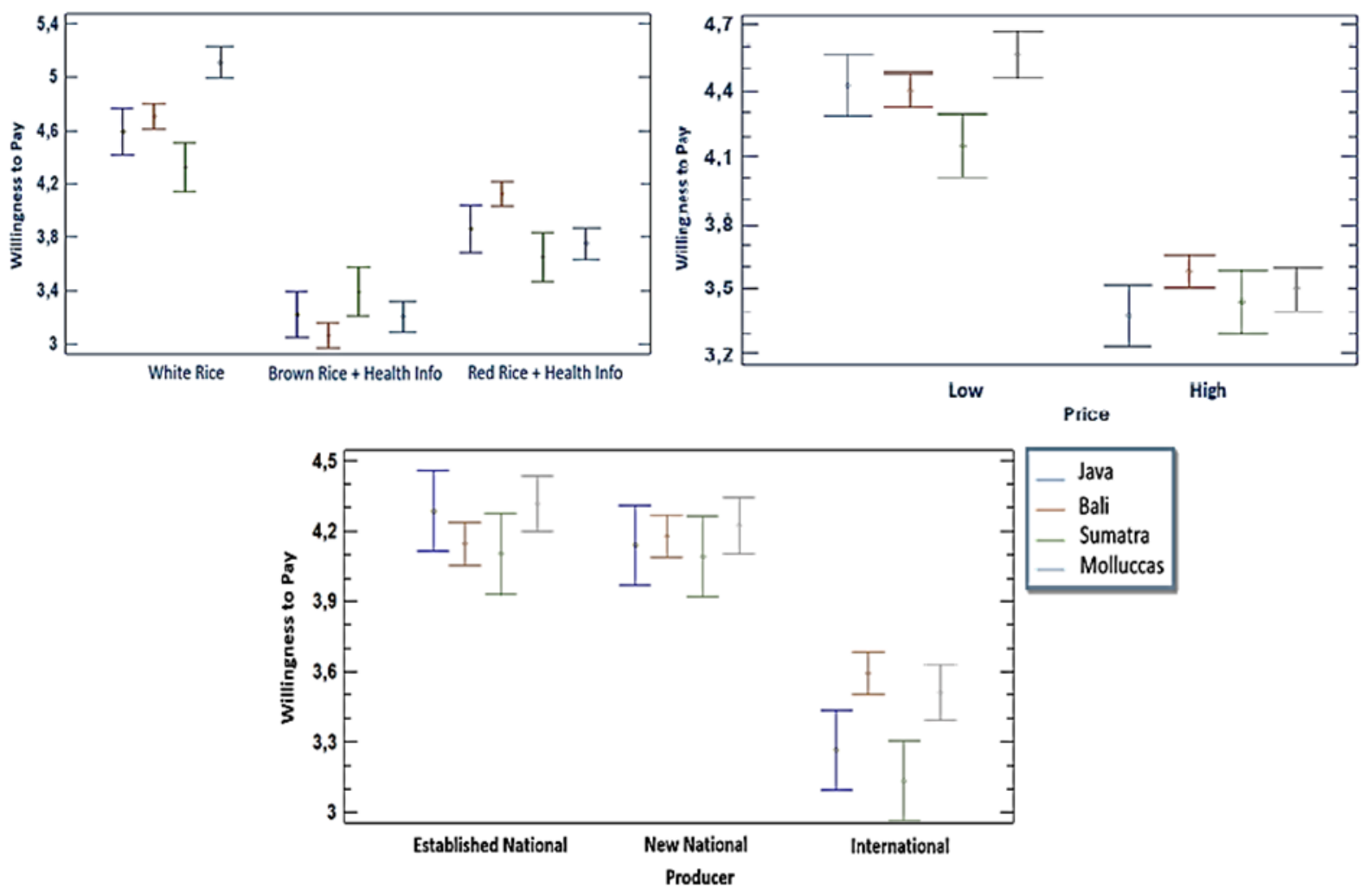

Figure 2. Influence of rice attributes on consumers' willingness to pay in Java, Bali, Sumatra, and the Moluccas islands for functional rice

Indonesian consumers value rice attributes and make their functional rice choices. Result in Figure 2 suggests that Indonesian consumers' willingness to pay was affected by the price, producer, and type of rice, while the presence of melatonin's health benefits on the label did not contribute a significant effect on their willingness to pay. Although the rice consumers in four islands significantly preferred polished white rice over the other types of rice, people in the Moluccas had a higher willingness to pay for polished white rice than those in Java, Bali, and Sumatra.

Indonesian consumers were most likely to buy rice at a lower price. Consumers in the Moluccas had the highest willingness to pay for rice at a low price while consumers in Sumatra had the lowest. The difference response might occur due to the difference in the regional minimum wage. On average, the regional minimum wage in Sumatra is higher than in the Moluccas (SI, 2017). People with higher incomes are more likely to afford the higher price of functional rice. Thus, the consumers in Sumatra were less willing to pay for the rice products at a low price than the consumers in the Moluccas.

In terms of rice producers, there was no significant difference between the new and the established national (Indonesian) producers for Indonesian consumers. Consumers in Java, Bali, Sumatra, and the Moluccas preferred national than the international rice producers. Interestingly, a positive willingness to pay for the international producer was discovered in Bali. This finding indicates that the Balinese were more open to the international market. It was a fair result taking into consideration that Bali is the island of Indonesia with the highest international tourists.

\subsection{Interaction of attributes affecting willingness to pay functional rice}

The price could likely influence the consumers to purchase a rice product. In this study, the relationship between price and types of rice on the willingness to pay was examined in the four islands. The result showed that regardless of the price, Indonesian consumers are more likely to prefer white rice over brown rice with a health claim (Figure 3). From the previously reported studies, Indonesian consumers have a significant preference for whiter or more polished rice products due to producing better palatability characteristics (Unnevehr et al., 1992; Swastika, 2012). It is general knowledge in Indonesia that there are hurdles to the consumption of brown rice since the grain is considered as poor-quality rice. The brown grain was considered to have a hard texture, chewy, and not appealing appearance (Mohan et al., 2017). Moreover, the willingness to pay for brown rice could also be associated with cultural values. The lack of awareness among Indonesian consumers on the benefit of brown rice might influence their willingness to pay.

The result in Figure 3 indicates that consumers in Java, Bali, and the Moluccas would be more willing to 

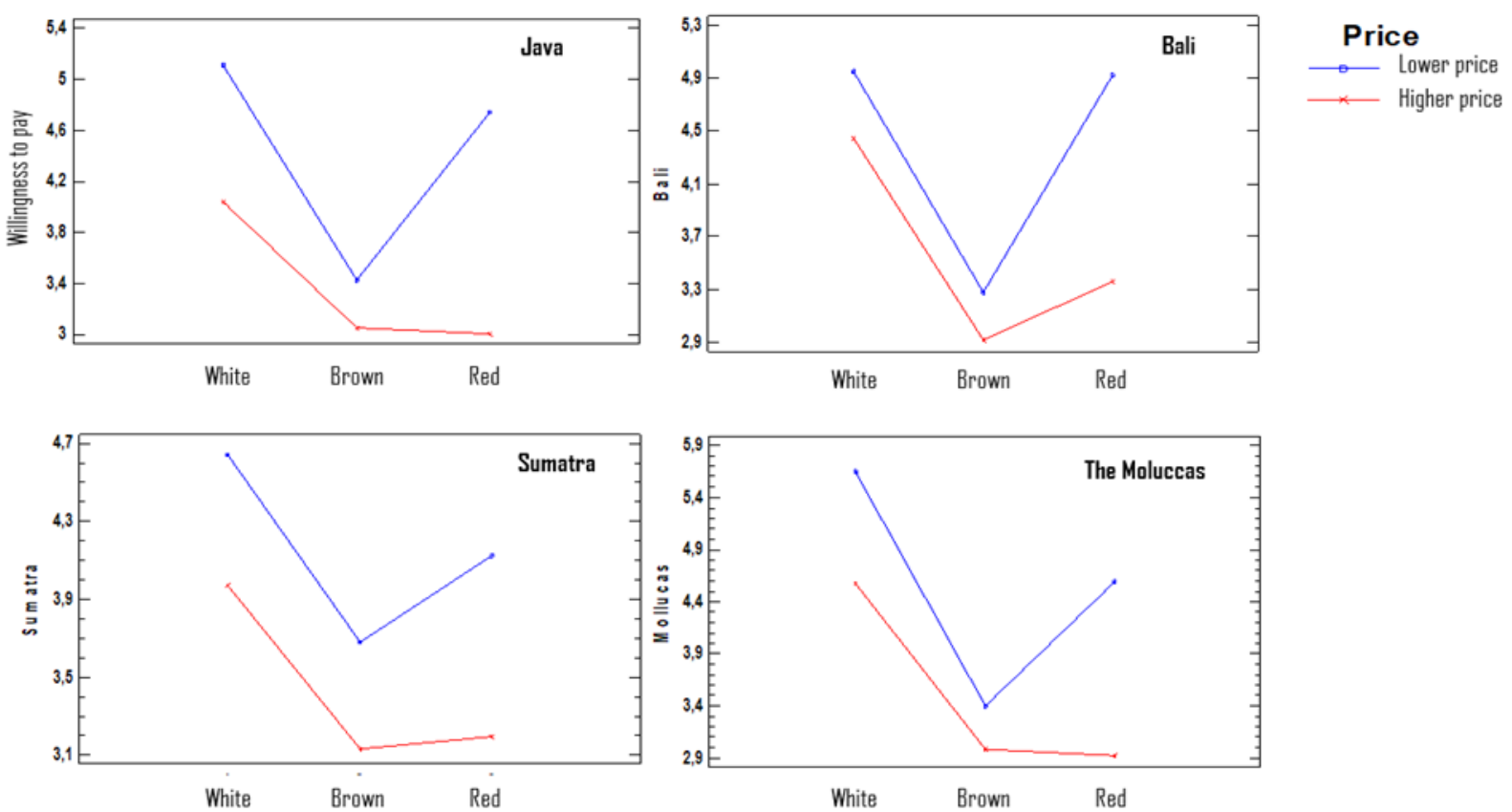

Figure 3. Interaction of price and type of rice on consumers' willingness to pay for functional rice.

pay for red rice with functional properties provided that the price was low. In addition, at a low price, the willingness to pay for the white and red rice was not significantly different $(p<0.05)$. This result could imply that consumers would buy functional red rice if the price was as low as conventional rice. The finding is relevant to a survey conducted in Denmark and England. The consumers expected functional foods to have the same price as conventional foods (Jonas and Beckmann, 1998). Another explanation is that the Indonesian consumer could not identify melatonin as a functional property on functional rice. Henceforth, they would not be willing to pay a higher price for functional rice if they are not convinced of the benefit of the product.

\subsection{Effect of demographic on consumers' willingness to pay}

The influence of demographic provided further insight into consumers' willingness to pay. Table 3 reveals that age, gender, marital status, occupation, and education levels did not significantly account for the willingness to pay $(p>0.05)$ of Indonesian consumers for functional rice. On the other hand, income had a significant impact on consumers' willingness to pay ( $p<$ 0.05).

Table 3. ANOVA summary of demographic profile on consumers' willingness to pay

\begin{tabular}{ccc}
\hline No & Demographic Profile & ANOVA $(p<0.05)$ \\
\hline 1 & Age & 0.064 \\
2 & Gender & 0.192 \\
3 & Marital status & 0.242 \\
4 & Occupation & 0.644 \\
5 & Education & 0.309 \\
6 & Income & $0.038^{*}$ \\
\hline
\end{tabular}

$*$ indicates significant at $p<0.05$
Although it has been reported that consumers care more about their health and take preventive action when growing older (Ares et al., 2010), there was only a moderate relation between the age of Indonesian consumers and willingness to pay for functional rice $(p=0.064)$. With respect to gender, a previous study reported that women had a more favorable interest in functional food than men (Verbeke, 2005). However, this generalization could not be applied to Indonesian consumers. As well as the gender, the willingness to pay for the functional rice was not affected by the level of education. A former study reported that respondents with higher levels of education have only a slightly more positive attitude towards functional foods (Urala and Lähteenmäki, 2007).

Interestingly, Indonesian respondents with high-level income were willing to pay more for functional rice compared to low and medium level income. This suggests that the additional price associated with functional rice with health benefits were more affordable for higher-income consumers.

\subsection{Consumer preference towards functional rice products in Indonesia}

The preference experiment explores how consumers value and make trade-offs among the selected attributes. Table 4 presents the ranking results of Indonesian consumers' willingness to pay for rice with a different type of rice, price, and producer. Product with lower rank showed that it was more preferred by the consumers. Indonesian consumers in four islands ranked white rice with both low and high prices, and both new and established Indonesian brands as their top preference. There was no significant difference in rating for 
Table 4. Ranking test result

\begin{tabular}{|c|c|c|c|c|c|c|c|c|c|c|}
\hline Product & Type of Rice & Price & Producer & Rank & & & & & & \\
\hline 3 & White & Low & Established Indonesian brand & 65 & $\mathrm{a}$ & & & & & \\
\hline 16 & White & Low & New Indonesian brand & 85 & $\mathrm{a}$ & $\mathrm{b}$ & & & & \\
\hline 17 & Red & Low & Established Indonesian brand & 87 & $\mathrm{a}$ & $\mathrm{b}$ & & & & \\
\hline 8 & White & High & Established Indonesian brand & 93 & a & $\mathrm{b}$ & $\mathrm{c}$ & & & \\
\hline 7 & Red & Low & New Indonesian brand & 99 & a & $\mathrm{b}$ & $\mathrm{c}$ & $\mathrm{d}$ & & \\
\hline 11 & White & High & New Indonesian brand & 109 & & $\mathrm{~b}$ & $\mathrm{c}$ & $\mathrm{d}$ & $\mathrm{e}$ & \\
\hline 2 & Brown & Low & New Indonesian brand & 112 & & $\mathrm{~b}$ & $\mathrm{c}$ & $\mathrm{d}$ & $\mathrm{e}$ & \\
\hline 4 & White & Low & International & 118 & & $\mathrm{~b}$ & $\mathrm{c}$ & $\mathrm{d}$ & $\mathrm{e}$ & $\mathrm{f}$ \\
\hline 12 & Brown & Low & Established Indonesian brand & 123 & & $\mathrm{~b}$ & $\mathrm{c}$ & $\mathrm{d}$ & $\mathrm{e}$ & $\mathrm{f}$ \\
\hline 15 & Brown & High & New Indonesian brand & 131 & & & $\mathrm{c}$ & $\mathrm{d}$ & e & $f$ \\
\hline 5 & Brown & High & Established Indonesian brand & 132 & & & $\mathrm{c}$ & $\mathrm{d}$ & $\mathrm{e}$ & $f$ \\
\hline 13 & White & High & International & 134 & & & & $\mathrm{~d}$ & $\mathrm{e}$ & $\mathrm{f}$ \\
\hline 14 & Red & Low & International & 134 & & & & $\mathrm{~d}$ & $\mathrm{e}$ & $\mathrm{f}$ \\
\hline 9 & Red & High & New Indonesian brand & 135 & & & & $\mathrm{~d}$ & $\mathrm{e}$ & $\mathrm{f}$ \\
\hline 6 & Brown & Low & International & 137 & & & & $\mathrm{~d}$ & $\mathrm{e}$ & $\mathrm{f}$ \\
\hline 10 & Red & High & Established Indonesian brand & 144 & & & & & $\mathrm{e}$ & $\mathrm{f}$ \\
\hline 1 & Red & High & International & 147 & & & & & e & $f$ \\
\hline 18 & Brown & High & International & 157 & & & & & & $\mathrm{f}$ \\
\hline
\end{tabular}

Rank sums with no letters in common are significantly different at the $5 \%$ significance level (Lrank $=40.17)$.

established Indonesian brands and new Indonesian brands (LSD < 40.17). The preference for red and brown rice with both new and established Indonesian bran was the same if the price was low. Whereas, red and brown rice products at a high price, regardless of the producer, were least preferred by consumers.

The Indonesian consumers preferred the national (new or established) brand over the international one. A previous study revealed a similar result for the Italian consumer (Ares et al., 2010; Annunziata and Vecchio, 2013). This interesting finding opens new functional rice market opportunities for Indonesian producers. The importance of brand familiarity needs to be emphasized. On top of that, the most effective strategy to make Indonesian consumers choose functional rice over the conventional one is by reducing the price of functional rice products.

\section{Conclusion}

The findings from this study provide interesting corroboration on how Indonesian consumers in four different islands appraise functional rice. Although they generally preferred conventional white rice, Indonesia consumers' willingness to pay for functional rice was significantly affected by the price. Another variable, rice producers, also had relative importance to the willingness to pay, which the consumers preferred the national over international producers. This finding opens potential opportunities to reinforce the Indonesian producer on functional rice.

\section{Conflict of interest}

The authors declare no conflict of interest.

\section{Acknowledgments}

Widiastuti Setyaningsih thanks financial support through Innovative Research Grant No. 677/FTP-UGM/ KU/2017 from Faculty of Agricultural Technology, Gadjah Mada University, Indonesia.

\section{References}

Annunziata, A. and Vecchio, R. (2013). Consumer perception of functional foods: A conjoint analysis with probiotics. Food Quality and Preference, 28(1), 348-355. https://doi.org/10.1016/ j.foodqual.2012.10.009

Ares, G., Giménez, A. and Deliza, R. (2010). Influence of three non-sensory factors on consumer choice of functional yogurts over regular ones. Food Quality and Preference, 21(4), 361-367. https:// doi.org/10.1016/j.foodqual.2009.09.002

Bonnefont-Rousselot, D. and Collin, F. (2010). Melatonin: Action as antioxidant and potential applications in human disease and aging. Toxicology, 278(1), 55-67. https://doi.org/10.1016/ j.tox.2010.04.008

Doyon, M. and Labrecque, J. (2008). Functional foods: a conceptual definition. British Food Journal, 110(11), 1133-1149.

https:// doi.org/10.1108/00070700810918036 
FAO (Food and Agriculture Organization). (2017). OECD-FAO Agricultural Outlook 2017-2026. Paris: OECD Publishing.

Ferracioli-Oda, E., Qawasmi, A. and Bloch, M. H. (2013). Meta-Analysis: Melatonin for the Treatment of Primary Sleep Disorders. Plos One, 8(5), e63773. https://doi.org/10.1371/journal.pone.0063773

Frewer, L., Scholderer, J. and Lambert, N. (2003). Consumer Acceptance of Functional Foods: Issues for the Future. British Food Journal, 105(10), 714 731. https://doi.org/10.1108/00070700310506263

ISO (International Organization for Standardization). (2011). ISO 29842: Sensory analysis-MethodologyBalanced incomplete block designs. ISO 29842:2011. Switzerland: ISO.

Jonas, M.S. and Beckmann, S.C. (1998). Functional foods: consumer perceptions in Denmark and England. England: Aarhus School of Business, MAPP Centre.

Lanfumey, L., Mongeau, R. and Hamon, M. (2013). Biological rhythms and melatonin in mood disorders and their treatments. Pharmacology and Therapeutics, 138(2), 176-184. https:// doi.org/10.1016/j.pharmthera.2013.01.005

Mauriz, J.L., Collado, P.S., Veneroso, C., Reiter, R.J. and González-Gallego, J. (2013). A review of the molecular aspects of melatonin's anti-inflammatory actions: Recent insights and new perspectives. Journal of Pineal Research, 54(1), 1-14. https:// doi.org/10.1111/j.1600-079X.2012.01014.x

Mohan, V., Ruchi, V., Gayathri, R., Ramya Bai, M., Shobana, S., Anjana, R.M., Unnikrishnan and R. Sudha, V. (2017). Hurdles in Brown Rice Consumption. In Manickavasagan, A., Chandini, S.K. and Venkatachalapathy, N. (Eds.), Brown Rice, p. 255-269. Springer International Publishing. https://doi.org/10.1007/978-3-319-59011-0 15

Setyaningsih, W., Duros, E., Palma, M. and Barroso, C.G.G. (2016). Optimization of the ultrasoundassisted extraction of melatonin from red rice (Oryza sativa) grains through a response surface methodology. Applied Acoustics, 103(Part B), 129135. https://doi.org/10.1016/j.apacoust.2015.04.001

Setyaningsih, W., Hidayah, N., Saputro, I.E., Palma, M. and Barroso, C.G. (2014). Melatonin Profile during Rice (Oryza Sativa) Production. Journal of Advanced Agricultural Technologies, 1(1), 60-64. https://doi.org/10.12720/joaat.1.1.60-64

SI. (2017). Statistics Indonesia: Upah Minimum Regional/Provinsi (UMR/UMP) dan rata-rata Nasional per tahun (Dalam Rupiah), 1997-2016. Indonesia: Badan Pusat Statistik. [In Bahasa
Indonesia].

Siró, I., Kápolna, E., Kápolna, B. and Lugasi, A. (2008). Functional food. Product development, marketing and consumer acceptance-a review. Appetite, 51(3), 456-467.

https://doi.org/10.1016/

j.appet.2008.05.060

Spiegelhalder, K., Nissen, C. and Riemann, D. (2017).

Clinical Sleep-Wake Disorders II: Focus on Insomnia and Circadian Rhythm Sleep Disorders. In Landolt, H.P. and Dijk, D.J. (Eds.). Sleep-Wake Neurobiology and Pharmacology. Handbook of Experimental Pharmacology. Berlin, Heidelberg: Springer. https://doi.org/10.1007/164_2017_40

Swastika, D.K.S. (2012). The role of post-harvest handling on rice quality in Indonesia. Forum Penelitian Agro Ekonomi, 30(1), 1-11. https:// doi.org/10.21082/fae.v30n1.2012.1-11

Szewczyk-Golec, K., Rajewski, P., Gackowski, M., Mila -Kierzenkowska, C., Wesołowski, R., Sutkowy, P., Pawłowska, M. and Woźniak, A. (2017). Melatonin Supplementation Lowers Oxidative Stress and Regulates Adipokines in Obese Patients on a Calorie -Restricted Diet. Oxidative Medicine and Cellular Longevity, 2017, $8494107 . \quad$ https:// doi.org/10.1155/2017/8494107

Unnevehr, L.J., Duff, B. and Juliano, B.O. (Eds.) (1992). Consumer Demand for Rice Grain Quality. Manila, Phillipines: The International Rice Research Institute.

Urala, N. and Lähteenmäki, L. (2003). Reasons behind consumers' functional food choices. Nutrition and Food Science, 33(4), 148-158. https:// doi.org/10.1108/00346650310488499

Urala, N. and Lähteenmäki, L. (2007). Consumers' changing attitudes towards functional foods. Food Quality and Preference, 18, 1-12. https:// doi.org/10.1016/j.foodqual.2005.06.007

Verbeke, W. (2005). Consumer acceptance of functional foods: socio-demographic, cognitive and attitudinal determinants. Food Quality and Preference, 16(1), $45-57$.

https://doi.org/10.1016/

j.foodqual.2004.01.001

Verbeke, W. (2006). Functional foods: Consumer willingness to compromise on taste for health? Food Quality and Preference, 17(1-2), 126-131. https:// doi.org/10.1016/j.foodqual.2005.03.003 